\title{
Mixed Integer Linear Programming Optimization of Multi-Node Transportation Transshipment Network
}

\author{
Abdul Salam Khan
}

NUST business School, National University of Sciences and Information technology (NUST), Islamabad, Pakistan

\begin{abstract}
Transportation network is time bound supply mechanism and it involves multiple levels. It is beneficial for an organization to identify optimal transportation routes by exploring different options. This practice can help in minimizing the transportation costs and Optimizing the delivery time. In this study, multiple levels of transportation transshipment network are considered and by adopting Mixed Integer Linear Programming (MILP), cost of transportation network is minimized. A comparison with the existing cost indices is provided for effectiveness of the tool used. Result indicates an improvement in the cost saving and comparison with the initial results suggests cost saving by $9.41 \%$ in transporting raw materials from depot to the factory level while $8.7 \%$ cost saving is achieved in transshipment of finished goods from warehouses to distribution centers. Overall, the total cost is reduced by $18.17 \%$ which is a significant improvement and can be translated into profit margin of the production supply chain. We also generalize the findings of the study by assessing the statistical robustness of the results.
\end{abstract}

Keywords: Transportation Network; Optimization; Mixed Integer Linear Programming; Statistical

Corresponding author's email: Abdulsalam_mechanical@yahoo.com

\section{INTRODUCTION}

Optimal selection of transportation-transshipment routes is a challenge faced by many vendors and inability to select the right combination of paths can cause a big dent to profit margins (UZ et al., 2014). Transshipment points are defined as points with zero inventory i.e., whatever is transported to such points are not stored for long, rather transferred to next locations (Kazemi et al., 2015). It is important to use warehouses, select acquisition paths, assign to inventories and target distribution points in a cost effective way and with higher response rate as time based delivery is appreciated by customers (Garcia et al., 2013). Network modeling presents a complex posture containing different segments, paths and decisions are required to use routes for optimal performance of supply chain (Wang et al., 2018). A robust analysis needs to be performed to analyze the different facets of transportation network supply chain such as delivery schedules, inventory usage and paths allocation (Yang et al., 2015). Transportation networks in particular are regularly monetarized and expanded as per the global trends and needs of congestion (Luathep et al., 2011). An existing supply chain network is considered with initial set of data indices against number of parts transported. Cost optimization analysis is carried out to enhance the performance of the transportation-transshipment network model. This study considers a transportation network comprising of four levels (raw material level $i$, factory level $j$, warehouse level $k$ and distribution level $l$ ) and decision is considered for number of parts transported between levels to optimize the transportation costs and delivery time. Mixed Integer Linear Programming (MILP) based mathematical model is used for optimization analysis. A thematic framework of the study model is provided in Figure 1 where four levels of transportation-transshipment network are considered.

\section{MATERIALS AND MATHODS}

The levels of transportation network are depots, factory, warehouses and distribution centers designated by $i, j, k \& l$, respectively. There are three choices for depots, single factory layout; four warehouses while two distribution centers to consider in the analysis. Assumptions and Mathematical model for study analysis is provided below;

Assumptions:

- All network nodes acts as transshipment nodes (no inventory storage)

- Inventory holding costs are assumed to be zero

- Opportunity costs for late delivery are not considered 
Mixed Integer Linear Programming Optimization of Multi-Node Transportation Transshipment Network

- Single product is considered where cost/unit transportation is same for all parts

- Loading and unloading costs are assumed to be insignificant
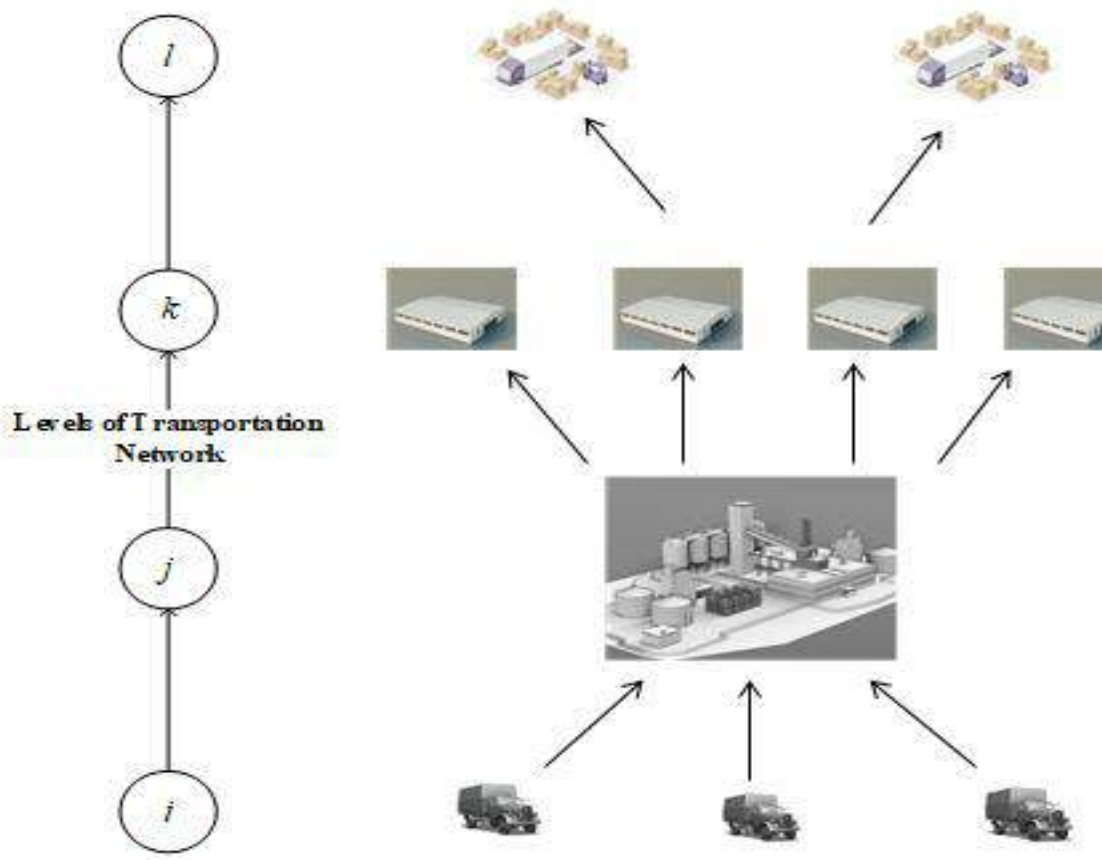

Distribution Centers

Warehouse

Figure 1: Layout of the Transportation Transshipment Network

Indexing

trasnporation-transhippment location $=\{i, j, k, l\}$

\section{Parameters}

$D=$ Total demand at factory \& distributioncenters

$C_{n}=$ perunit transportation $\cos t$ at $n ;$ where $n=\{i, j, k, l\}$

$C_{i j}=$ per unit cost from depot $i$ to factory $j$

$C_{j k}=$ per unit cost from factory $j$ to warehouse $k$

$C_{k l}=$ per unit cost from warehouse $k$ to distribution center $l$

Caiq $=$ Capacity constraint at depot $i$ \& center $q$ where $q=\{1,2,3\}$

Cakr $=$ Capacity constraint at warehouse $k$ \& center $t$ where $t=\{1,2,3,4\}$

Calp $=$ Capacity constraint at distribution / \& center $p$ where $p=\{1,2\}$

$Z_{i j}=$ number of products transhipped from depot $i$ to factory $j$

$Z_{j k}=$ number of products transhipped from factory $j$ to warehouse $k$ 
$Z_{k l}=$ number of products transhipped from warehouse $k$ to distributioncenter 1

\section{DecisionVariables}

$X_{i j}, X_{j k}, X_{k l}$ binary decision variable; where,

$$
\begin{aligned}
& X_{i j}=\left\{\begin{array}{l}
0, \text { if path } i j \text { is not selected } \\
1, \text { if path } i j \text { is selected }
\end{array}\right\} \\
& X_{j k}=\left\{\begin{array}{l}
0, \text { if path } j k \text { is not selected } \\
1, \text { if path } j k \text { is selected }
\end{array}\right\} \\
& X_{k l}=\left\{\begin{array}{l}
0, \text { if path } k l \text { is not selected } \\
1, \text { if path } k l \text { is selected }
\end{array}\right\}
\end{aligned}
$$

The network diagram and associated data is shown in Figure 2 below. There are four distinct levels of the analysis and also, the distances between two respective connection points is displayed on the arrow head. For example, from depot 1 to the factory, distance is $30 \mathrm{~km}$. Similarly, second warehouse and the first distribution center are separated by distance of $49 \mathrm{~km}$.

Table 1 contains the maximum capacity at each raw material depot for supply to the factory, distance associated between respective depot point and factory, and transportation cost per item between the supply points.

Table 2 contains capacity, distance and cost indices between the warehouse locations and factory. There is an upper limit on the number of transported parts between the warehouse and the factory location which are used in the mathematical functions of depots, factory, warehouse and the distribution centers.

Table 3 represents cost and distance relationship between 4 warehouse locations and 2 distribution points. The maximum capacity at each distribution point is 2200 and 2400 units respectively (also equal to total demand $D$ ).

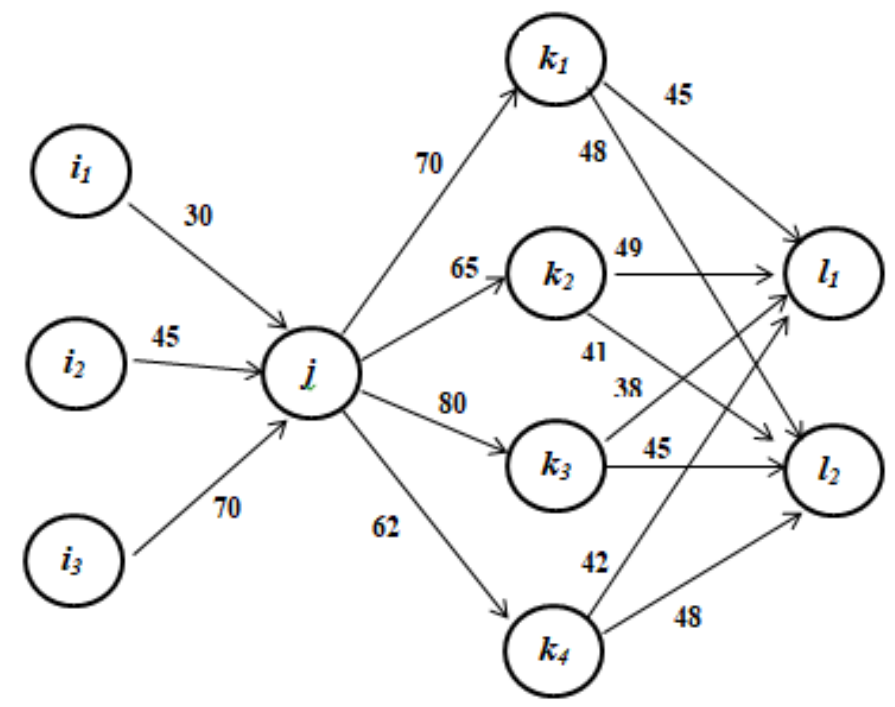

Figure 2: Network diagram for the distribution system: Values on arrows represents transportation distance between nodes 
Mixed Integer Linear Programming Optimization of Multi-Node Transportation Transshipment Network

Table 1: Transportation capacity, distance and cost between depots and factory

\begin{tabular}{|c|c|c|c|c|}
\hline Depot & Max. Capacity & Distance from j & Cost/part/km & Cost/part \\
\hline$i_{1}$ & 1600 Units & $30 \mathrm{Km}$ & $\$ 0.2$ & $\$ 6$ \\
\hline$i_{2}$ & 1500 Units & $45 \mathrm{Km}$ & $\$ 0.17$ & $\$ 7.65$ \\
\hline$i_{3}$ & 1850 Units & $70 \mathrm{Km}$ & $\$ 0.24$ & $\$ 16.8$ \\
\hline $\begin{array}{c}\text { Max. } \\
\text { Supply }\end{array}$ & 4950 Units & --- & -- & \\
\hline
\end{tabular}

Table 2: Capacity, distance and cost figures between warehouse(s) and factory

\begin{tabular}{|c|c|c|c|c|}
\hline Warehouse & Max Capacity & $\begin{array}{c}\text { Distance from } \\
\text { Factory }\end{array}$ & $\begin{array}{c}\text { Trans. } \\
\text { Cost/Unit/Km }\end{array}$ & $\begin{array}{c}\text { Trans. } \\
\text { Cost/Unit }\end{array}$ \\
\hline$K_{1}$ & 1400 Units & $70 \mathrm{Km}$ & $\$ 0.3$ & $\$ 21$ \\
\hline$K_{2}$ & 1400 Units & $65 \mathrm{Km}$ & $\$ 0.28$ & $\$ 18.2$ \\
\hline$K_{3}$ & 950 Units & $80 \mathrm{Km}$ & $\$ 0.29$ & $\$ 23.2$ \\
\hline$K_{4}$ & 1600 Units & $62 \mathrm{Km}$ & $\$ 0.34$ & $\$ 21.08$ \\
\hline
\end{tabular}

Table 3: Capacity, distance and cost between warehouse(s) and distribution center(s)

\begin{tabular}{|c|c|c|c|c|c|c|}
\hline \multirow[b]{2}{*}{ Distribution } & \multicolumn{4}{|c|}{ Warehouse (Distance) } & \multicolumn{2}{|c|}{$\begin{array}{c}\text { Maximum } \\
\text { Capacity }\end{array}$} \\
\hline & $K_{1}$ & $K_{2}$ & $K_{3}$ & $K_{4}$ & & 12 \\
\hline$I_{1}$ & $\begin{array}{l}45 \\
\mathrm{Km}\end{array}$ & $49 \mathrm{Km}$ & $38 \mathrm{Km}$ & $42 \mathrm{Km}$ & \multirow{5}{*}{$\begin{array}{l}2200 \\
\text { Units }\end{array}$} & \multirow{5}{*}{$\begin{array}{l}2400 \\
\text { Units }\end{array}$} \\
\hline \multirow[t]{2}{*}{$I_{2}$} & $\begin{array}{l}54 \\
\mathrm{Km}\end{array}$ & $41 \mathrm{Km}$ & $45 \mathrm{Km}$ & $48 \mathrm{Km}$ & & \\
\hline & \multicolumn{4}{|c|}{ Transportation Cost/Unit } & & \\
\hline$l_{1}$ & $\begin{array}{c}\$ 25.6 \\
5\end{array}$ & $\$ 29.89$ & $\$ 14.06$ & $\$ 16.38$ & & \\
\hline$l_{2}$ & $\begin{array}{c}\$ 22.1 \\
4\end{array}$ & $\$ 15.99$ & $\$ 24.3$ & $\$ 22.56$ & & \\
\hline
\end{tabular}

Objective function

Min

$\sum_{\substack{i=1 \\ j=1}}^{i=3} X_{i j} C_{i j} Z_{i j}+\sum_{\substack{j=1 \\ k=1}}^{k=4} X_{j k} C_{j k} Z_{j k}+\sum_{\substack{k=1 \\ l=1}}^{\substack{l=2 \\ k=4}} X_{k} C_{k l} Z_{k l}$

$S . t$

$Z_{i j}-Z_{j k}=0$

$Z_{j k}-Z_{k l}=0$

$\sum_{\substack{k=1 \\ l=1}}^{\substack{l=2 \\ k=4}} Z_{i l}<D$

$\sum_{i=1}^{1 / 3} C_{i 1}<4950$

$C_{1 j} \leq 1600$

$C_{2 j} \leq 1500$

$C_{3 j} \leq 1800$ 


$C_{j 1} \leq 1400$
$C_{j 2} \leq 1100$
$C_{j 3} \leq 800$
$C_{j 4} \leq 1300$
$C_{k 1} \leq 2200$
$C_{k 2} \leq 2400$

Objective function is the sum product of cost of transportation between points and number of parts being transferred provided that a particular path is selected for transportation. The objective function minimizes the cost of parts transshipped in the supply chain network.

Constraints $1 \& 2$ is to ascertain that depots, factory and warehouses serve as transshipment nodes where no part is retained or inventoried (zero inventory handling costs). Constraint 3 is the demand tolerance for the distribution centers; its capacity cannot exceed from demand in regions. Similarly, supply equals demand constraint which is 4950 combining the demand of both distribution centers (constraint 4). Constraint 5,6 \& 7 is to make sure that supply from three depots does not exceed than their respective capacities of 1600 , 1500 and 1850 units. Similarly, products flow from factory to the respective warehouses should be within the capacity limits of warehouses (constraint $8,9,10 \& 11$ ). Lastly, product flow from the warehouses to distribution centers should not exceed requirement at respective distribution centers $I_{1} \& I_{2}(2200 \& 2400$ Units respectively; Constraint 12 \& 13). The optimization analysis was performed using Mixed Integer Linear Programming (MILP) in LINGO software and Excel solver. The optimized analysis results are compared with the initial statistics for assessing performance in the next section.

\section{RESULTS AND DISCUSSION}

Results of MILP analysis are provided in Table 4 where a comparison between initial data indices and optimization efforts is displayed for both parts transported and cost of transportation. It can be noted that as a result of analysis, cost was minimized \& although between figures there is a mix trend but overall cost of transportation from depot to factory level decreased by $9.41 \%$. Similarly, the cost of transporting goods from warehouses $\left(K_{1}-K_{4}\right)$ to the distribution centers $\left(I_{1} \& I_{2}\right)$ was reduced by $8.7 \%$. To conclude the results, cost effectiveness of $18.7 \%$ was accomplished as a result of the optimization effort which translates to an amount of $\$ 15629$. Initial cost of transportation was calculated to be $\$ 152472$ while the resulted optimized cost was equal to $\$ 136843$.

Table 4: Optimization results of transportation between points and comparison with initial indices

\begin{tabular}{|c|c|c|c|c|c|c|c|c|c|c|c|c|}
\hline & & $i_{1}-j$ & $i_{2}-j$ & $i_{3}-j$ & $K_{1}-I_{1}$ & $K_{2}-I_{1}$ & $K_{3}-I_{1}$ & $K_{4}-I_{1}$ & $K_{1}-I_{2}$ & $K_{2}-I_{2}$ & $K_{3}-I_{2}$ & $K_{4}-I_{2}$ \\
\hline \multirow{2}{*}{ Parts } & Initial & 1340 & 1460 & 1800 & 650 & 750 & 220 & 580 & 500 & 580 & 700 & 620 \\
\hline & Optimized & 1580 & 1495 & 1525 & 350 & 240 & 760 & 850 & 460 & 785 & 435 & 720 \\
\hline \multirow{2}{*}{ Cost } & Initial & 8040 & 11169 & 30240 & 16672 & 22417 & 3093 & 9500 & 11070 & 9274 & 17010 & 13987 \\
\hline & Optimized & 9480 & 11436 & 25620 & 8977 & 7173 & 10685 & 13923 & 10184 & 12552 & 10570 & 16243 \\
\hline
\end{tabular}

Figure 3 provides graphical comparison of the number of parts and cost of transportation, before and after the analysis. From the graph of parts transported, it is evident that the optimized number of parts transported is greater at each point from initial set of data whereas, there is a mix trend in the cost of transportation between points and from the graph, cost of transportation after the analysis is greater at four points $\left(K_{1}-I_{1}\right.$, $\left.K_{4}-I_{1}, K_{1}-I_{2} \& K_{3}-I_{1}\right)$ while there is a break even at two point $\left(i_{2}-j \& K_{2}-I_{2}\right)$. In order to validate that the results are valid and generalizable, an analysis is performed using paired sample $t$-test (Mee et al., 1991) in SPSS V.22 and findings are discussed in the next portion. 


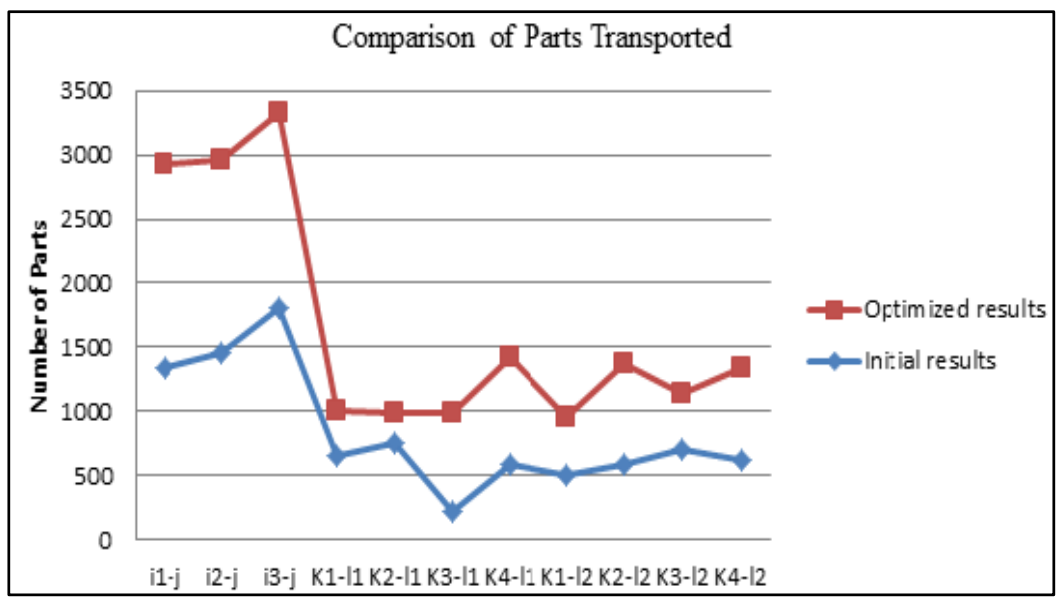

Figure 3: Graphical representation of Parts and Cost comparison

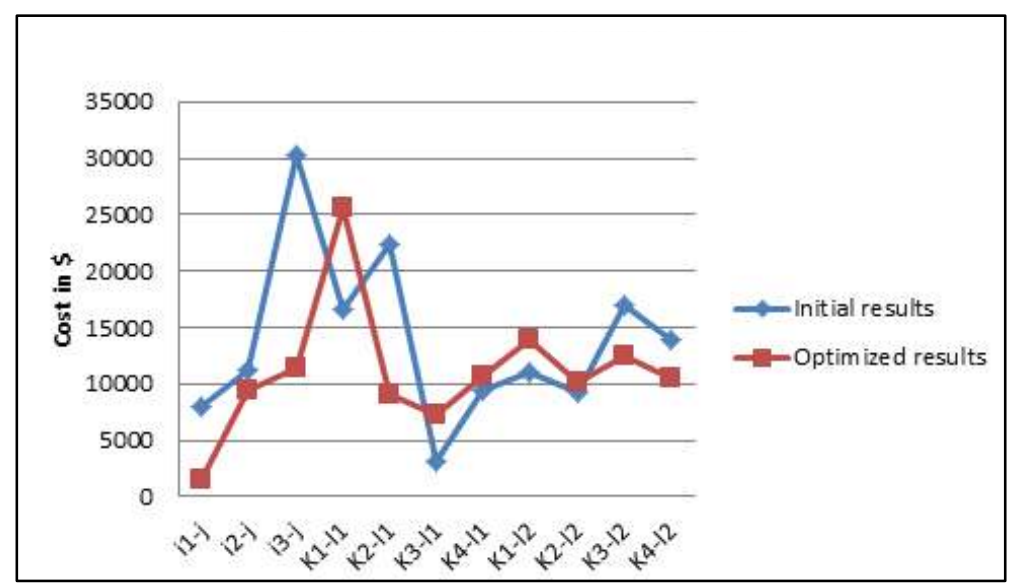

Figure 4: Graphical representation of Transportation Cost comparison

Table 5 contains the results of paired sample $t$-test (Ross et al., 2017). From the mean score column, we can understand that difference in the mean score for parts transported before and after the optimization is zero $(M=0 ; S . D=311.9)$ as in both cases, overall same number of parts were transported (which is equal to demand, D) but the difference in the patterns exhibited by earlier plot is significant. Similarly, pair 2 is the comparison of cost (before and after the optimization analysis) with a Mean=1420.818 (S.D=6543.4) which is also significant $(p<0.05)$ with a $p$-value equal to 0.048 . This can be interpreted as cost of transportation on average is $\$ 1420.818$ ( $t$-value equals 0.720 ) more in the case of an un-optimized environment. Thus, we can conclude that the results are generalizable and earlier attained results hold true for larger contexts. Future research can focus on considering the delivery time indices of the same network models and an analysis can be carried out to compare the delivery time schedules in an optimized and un-optimized environment. Also, these findings can be applied and replicated in other study contexts for enhancing the robustness of the methodological approach. Uncertainty factors were not considered in the analysis which are practical in today's production and supply chain environment, future focus can incorporate the uncertainty factors in the MILP analysis to provide more meaningful insights. 
Mixed Integer Linear Programming Optimization of Multi-Node Transportation Transshipment Network

Table 5: Paired sample comparison for cost and parts transported

\begin{tabular}{|c|c|c|c|c|c|c|c|}
\hline \multicolumn{8}{|c|}{ Paired Samples Test } \\
\hline & & \multicolumn{3}{|c|}{ Paired Differences } & \multirow[t]{2}{*}{$\mathrm{t}$} & \multirow[t]{2}{*}{ Df } & \multirow[t]{2}{*}{ Sig. (2-tailed) } \\
\hline & & Mean & S.D & $\begin{array}{c}\text { Std. Err. } \\
\text { Mean }\end{array}$ & & & \\
\hline Pair 1 & $\begin{array}{l}\text { Init_Parts - } \\
\text { Opt_Parts }\end{array}$ & .000 & 311.9 & 94.045 & .000 & 10 & .004 \\
\hline Pair 2 & Init_Cost - Opt_Cost & 1420.818 & 6543.4 & 1972.932 & .720 & 10 & .048 \\
\hline
\end{tabular}

\section{REFERENCES}

- Garcia J, Florez, JE, Torralba A, Borrajo D, Lopez L, García-Olaya A, Saenz, J. (2013). Combining linear programming and automated planning to solve intermodal transportation problems. European Journal of Operational Research 227(1):216-226.

- Kazemi Y, Szmerekovsky J. (2015). Modeling downstream petroleum supply chain: the importance of multi-mode transportation to strategic planning. Transportation Research Part E: Logistics and Transportation Review 83:111-125.

- Luathep P, Sumalee A, Lam WH, Li Z.C, Lo HK. (2011). Global optimization method for mixed transportation network design problem: a mixed-integer linear programming approach. Transportation Research Part B: Methodological 45(5):808-827.

- Mee, RW, Chua TC. (1991). Regression toward the mean and the paired sample t test. The American Statistician 45(1):39-42.

- Ross A, Willson VL. (2017). Paired Samples T-Test. In Basic and Advanced Statistical Tests. Sense Publishers Rotterdam, pp. 17-19.

- M Hakan AKYUZ, Chung-Yee LEE. (2014). Service level assignment and container routing for liner shipping service networks. In Proceedings of the International Multi-Conference of Engineers and Computer Scientists, Vol. 2.

- Wang Y, Zhang N, Zhuo Z, Kang C, Kirschen D. (2018). Mixed-integer linear programming-based optimal configuration planning for energy hub: Starting from scratch. Applied Energy 210:1141-1150.

- Yang Y, Zhang S, Xiao Y. (2015). An MILP (mixed integer linear programming) model for optimal design of district-scale distributed energy resource systems. Energy 90:1901-1915. 